\title{
Viscous organic aerosol particles in the upper troposphere: diffusivity-controlled water uptake and ice nucleation?
}

\author{
D. M. Lienhard ${ }^{1, a}$, A. J. Huisman ${ }^{1, b}$, U. K. Krieger ${ }^{1}$, Y. Rudich ${ }^{2}$, C. Marcolli ${ }^{1,3}$, B. P. Luo ${ }^{1,4}$, D. L. Bones ${ }^{5, c}$, J. P. Reid ${ }^{5}$, \\ A. T. Lambe ${ }^{6,7}$, M. R. Canagaratna ${ }^{7}$, P. Davidovits ${ }^{6}$, T. B. Onasch ${ }^{6,7}$, D. R. Worsnop ${ }^{7}$, S. S. Steimer ${ }^{1,8}$, T. Koop ${ }^{9}$, and \\ T. Peter ${ }^{1}$ \\ ${ }^{1}$ Institute for Atmospheric and Climate Science, ETH Zürich, 8092 Zürich, Switzerland \\ ${ }^{2}$ Department of Environmental Sciences, Weizmann Institute, Rehovot 76100, Israel \\ ${ }^{3}$ Marcolli Chemistry and Physics Consulting GmbH, 8092 Zürich, Switzerland \\ ${ }^{4}$ Physikalisch-Meteorologisches Observatorium Davos and World Radiation Center PMOD/WRC, 7260 Davos, Switzerland \\ ${ }^{5}$ School of Chemistry, University of Bristol, BS8 1TS Bristol, UK \\ ${ }^{6}$ Chemistry Department, Boston College, Chestnut Hill, MA 02467, USA \\ ${ }^{7}$ Aerodyne Research Inc., Billerica, MA 01821, USA \\ ${ }^{8}$ Laboratory of Radiochemistry and Environmental Chemistry, Paul Scherrer Institute, 5232 Villigen, Switzerland \\ ${ }^{9}$ Faculty of Chemistry, Bielefeld University, 33615 Bielefeld, Germany \\ a present address: Department of Chemistry, University of Cambridge, Cambridge, UK \\ b present address: Chemistry Department, Union College, Schenectady, NY, USA \\ ${ }^{c}$ present address: School of Chemistry, University of Leeds, Leeds, UK
}

Correspondence to: U. Krieger (ulrich.krieger@env.ethz.ch)

Received: 20 August 2015 - Published in Atmos. Chem. Phys. Discuss.: 9 September 2015

Revised: 19 November 2015 - Accepted: 25 November 2015 - Published: 9 December 2015

\begin{abstract}
New measurements of water diffusion in secondary organic aerosol (SOA) material produced by oxidation of $\alpha$-pinene and in a number of organic/inorganic model mixtures (3-methylbutane-1,2,3-tricarboxylic acid (3MBTCA), levoglucosan, levoglucosan/ $\mathrm{NH}_{4} \mathrm{HSO}_{4}$, raffinose) are presented. These indicate that water diffusion coefficients are determined by several properties of the aerosol substance and cannot be inferred from the glass transition temperature or bouncing properties. Our results suggest that water diffusion in SOA particles is faster than often assumed and imposes no significant kinetic limitation on water uptake and release at temperatures above $220 \mathrm{~K}$. The fast diffusion of water suggests that heterogeneous ice nucleation on a glassy core is very unlikely in these systems. At temperatures below $220 \mathrm{~K}$, model simulations of SOA particles suggest that heterogeneous ice nucleation may occur in the immersion mode on glassy cores which remain embedded in a liquid shell when experiencing fast updraft velocities. The particles absorb significant quantities of water during these updrafts which plasticize their outer layers such that these layers equi-
\end{abstract}

librate readily with the gas phase humidity before the homogeneous ice nucleation threshold is reached. Glass formation is thus unlikely to restrict homogeneous ice nucleation. Only under most extreme conditions near the very high tropical tropopause may the homogeneous ice nucleation rate coefficient be reduced as a consequence of slow condensed-phase water diffusion. Since the differences between the behavior limited or non limited by diffusion are small even at the very high tropical tropopause, condensed-phase water diffusivity is unlikely to have significant consequences on the direct climatic effects of SOA particles under tropospheric conditions.

\section{Introduction}

Recent field measurements showed that secondary organic aerosol (SOA) particles are often amorphous glasses under dry and/or cold conditions (Virtanen et al., 2010). This observation is consistent with the glass-forming properties of 
many organic components of atmospheric particles (Zobrist et al., 2008; Koop et al., 2011). Further, it has been shown that chemical and physical processes occurring in the interior of the particle and at the gas/condensate interface are influenced by the viscous state in which condensed-phase diffusion is expected to slow down considerably (Debenedetti, 1996; Booth et al., 2014; Berkemeier et al., 2014). A much reduced water diffusivity slows down the growth of droplets compared with that predicted by equilibrium thermodynamics, but its significance for the ability of the droplets to act as ice nuclei or provide a medium for multi-phase chemistry is still poorly quantified (Murray et al., 2010; Shiraiwa et al., 2011; Koop et al., 2011; Price et al., 2015). This is mainly because viscosity, bounce factors and glass transition temperatures only provide indirect evidence for kinetic limitations of water diffusivity, whereas diffusion coefficients in the amorphous state span many orders of magnitude. Previous studies investigated the viscosity of atmospherically relevant model systems at around room temperature and used the StokesEinstein relation to derive diffusion coefficients (RenbaumWolff et al., 2013; Hosny et al., 2013; Power et al., 2013; Abramson et al., 2013; Booth et al., 2014; Zhang et al., 2015). However, diffusivity and viscosity decouple below approximately $1.2 T_{\mathrm{g}}$ or higher, where $T_{\mathrm{g}}$ refers to the thermal glass transition temperature as measured by differential scanning calorimetry (Mapes et al., 2006; Corti et al., 2008). As a result of this decoupling, diffusion coefficients predicted with the Stokes-Einstein relation may be orders of magnitude smaller than observed (Molinero and Goddard, 2005; Power et al., 2013). In addition, the relationship between the viscosity of mixtures such as aqueous solutions of SOA materials and the diffusion coefficients of the different components present in the solution is not well characterized.

Only a few studies have measured the diffusion of water in glassy model systems for atmospherically relevant relative humidities at room temperature and even fewer studies at lower temperatures (Zobrist et al., 2011; Tong et al., 2011; Bones et al., 2012; Price et al., 2014; Lienhard et al., 2014; Steimer et al., 2015). Estimations of the influence of slow water diffusivity on homogeneous and heterogeneous ice nucleation as well as on multi-phase chemistry have been extrapolated from sucrose properties as a model system towards different types of SOA (Berkemeier et al., 2014; Arangio et al., 2015). Only very recently Price et al. (2015) reported water diffusivities in $\alpha$-pinene secondary organic material (SOM) using a Raman isotope tracer method.

In this study we present measurements of water diffusion in levitated aerosol particles for a few binary model compounds representing SOA as well as in chamber-generated $\alpha$-pinene SOA material that cover a large range of atmospherically relevant conditions. We then use these new data to investigate how water diffusion affects the ability of such particles to act as cloud condensation and ice nuclei.

\section{Methods}

The response time of organic particles to changes in relative humidity $(\mathrm{RH})$ is studied by observing the change in the mass and size of single levitated organic particles of different compositions between 206.5 and $291 \mathrm{~K}$ and relative humidities up to 0.7 . The method to determine water diffusion coefficients, $D_{\mathrm{w}}\left(T, a_{\mathrm{w}}\right)$, from such experiments as a function of temperature and water activity, $a_{\mathrm{w}}$, has been described in detail previously (Zobrist et al., 2011; Lienhard et al., 2014; Steimer et al., 2015). In short, we use a double ring electrodynamic balance (EDB) in a three-wall glass chamber with a circulating cooling liquid between the innermost two walls which controls the temperature with a stability better than $0.1 \mathrm{~K}$ and accuracy of $\pm 0.5 \mathrm{~K}$ and an insulation vacuum between the outer walls. Single particles are injected using a Hewlett Packard 51633A ink jet cartridge and are inductively charged, thus allowing levitation by the electric fields generated by two ring electrodes (AC field) and two end-cap electrodes (DC field, which tracks the mass change of the particle when the RH is changed). The RH in the EDB is controlled by adjusting the flows of dry and humidified nitrogen gas via mass flow controllers. The levitated particle is illuminated by a HeNe laser (633 nm), an LED (560 to $610 \mathrm{~nm}$ ) and a narrow bandwidth tunable diode laser (765 to $781 \mathrm{~nm}$ ) which allow tracking of changes in composition and size by analyzing resonances in the Mie scattering spectra (Lienhard et al., 2014; Steimer et al., 2015). Mass and radius growth factors as well as density and refractive index of the particles can be derived from these measurements over the entire concentration range after allowing sufficient time for equilibration (Lienhard et al., 2012a; Steimer et al., 2015) (examples are given in Appendix A3). Note that the mass fraction of solute can be directly inferred from the mass growth factor, without knowledge of the molar mass of the solute. In addition, the volatility of solutes can be determined by measuring evaporation rates (Zardini et al., 2006).

The changes in composition and size of the droplets upon varying the conditions in the chamber are compared to predictions from a diffusion model (Zobrist et al., 2011; Lienhard et al., 2014). The numerical model subdivides the particle into up to several thousand individual shells and solves the non-linear diffusion equation in spherical coordinates while accounting for the concentration dependence of the water diffusion coefficient, i.e. accounting for the plasticizing effect of water (Zobrist et al., 2011; Lienhard et al., 2014; Steimer et al., 2015). The number of shells and the timesteps are adjusted dynamically to provide numerical stability. The minimum width of the shells are kept larger than the molecular dimension of water of about $0.3 \mathrm{~nm}$. The diffusion coefficients of the solutes investigated in this study are expected to be much slower than that of water and are thus not accounted for in the calculations.

We measured water diffusion coefficients in a few model systems representing organic aerosol: raffinose 
(Sigma, 98\%), levoglucosan (ABCR, 99\%) and a levoglucosan $/ \mathrm{NH}_{4} \mathrm{HSO}_{4}$ mixture were used without further purification. 3-MBTCA, a second generation oxidation product of $\alpha$-pinene, was synthesized as described by Dette et al. (2014). The $\alpha$-pinene SOA samples investigated in this study were generated with a Potential Aerosol Mass (PAM) flow tube reactor as described in detail by Lambe et al. (2011) from the gas phase oxidation of $\alpha$-pinene with $\mathrm{OH}$ radicals and collected onto $47 \mathrm{~mm}$ teflon filters. To collect sufficient sample mass $(4-5 \mathrm{mg})$ for the offline analysis, steady-state SOA mass concentrations of approximately $300-400 \mu \mathrm{g} \mathrm{m}^{-3}$ were produced in the reactor and collected at $8.5 \mathrm{~L} \mathrm{~min}^{-1}$ for $24 \mathrm{~h}$. In order to prepare injection into the EDB, the material was extracted from the filter with methanol which was subsequently evaporated in $\mathrm{N}_{2}$ gas. It was shown previously that the extraction in methanol does not significantly change the optical properties or the composition of the extract (Heaton et al., 2009; Lambe et al., 2013). Accurate weighing before and after the extraction confirmed that all the material was extracted from the filter. An aerodyne time-of-flight aerosol mass spectrometer was used to calculate the $\mathrm{O}: \mathrm{C}$ and $\mathrm{H}: \mathrm{C}$ ratios of $\alpha$-pinene SOA of 0.53 and 1.50 , respectively.

\section{Results and discussion}

Figure 1 shows an example of the experimental data together with results from the diffusion model for an $\alpha$-pinene SOA particle levitated at $263 \mathrm{~K}$. The relative humidity is shown in panels (a) and (c) with the corresponding size changes shown in panels (b) and (d), respectively. These size changes do not follow the thermodynamic growth curve (gray lines, calculated according to the parametrizations in Appendix A3) but show an impeded response upon drying and humidifying. This response is compared to three predictions from the diffusion model which assume different concentration dependences of $D_{\mathrm{w}}$ covering about one order of magnitude, shown in panel (e). Although the agreement between measurement and simulation is not perfect for all calculations, the upper curve in panel (e) (orange line) results in a significantly faster response while the lower curve (blue line) results in a significantly slower response than observed. The uncertainty associated with the concentration dependence of $D_{\mathrm{w}}$ as derived from one individual experiment as shown in Fig. 1 is thus smaller than the range between the orange and the blue line in panel (e), but we estimate the uncertainty to be one order of magnitude to account for differences between the individual experiments.

It was recently suggested by Pajunoja et al. (2015) that the water uptake by slightly oxygenated SOA particles under subsaturated conditions is dominated by adsorption processes and that the low solubility inhibits water uptake rather than slow diffusion. These findings are in contrast to the water uptake of a SOA particle shown in Fig. 1c which
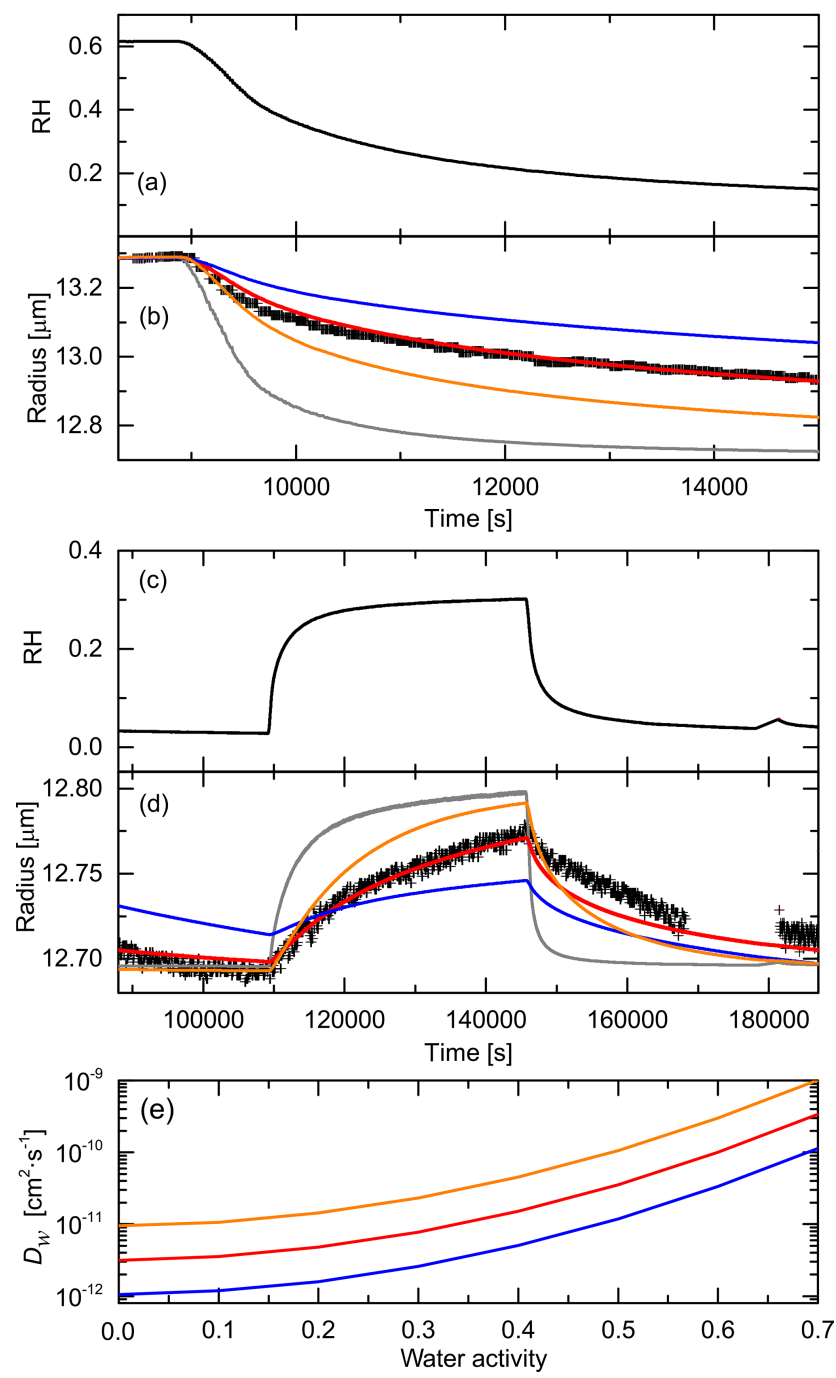

Figure 1. Experimental data of the hygroscopic response of an SOA particle levitated in the EDB at $263 \mathrm{~K}$ that was initially equilibrated at $60 \%$ RH. (a) and (c): change in RH upon drying and humidifying. (b) and (d): corresponding size change measured by Mieresonance spectroscopy (black crosses) together with the response expected based on the thermodynamic properties (gray lines) and the predictions from the diffusion model (red lines). The orange and blue lines represent the upper and lower limits of the uncertainty range associated with the concentration dependence of the water diffusion coefficients, $D_{\mathrm{w}}$, shown in panel (e). The values of $D_{\mathrm{W}}$ at water activity intervals of about 0.1 were used to produce the temperature and concentration dependent fit shown in Fig. 2a.

shows a growth of more than $50 \mathrm{~nm}$ upon a change in relative humidity from close to 0.0 to about 0.3 . This growth is much larger than can be expected based on surface adsorption alone. Hence we believe that the water uptake of the $\alpha$-pinene SOA particles investigated in this study was limited by water diffusion rather than solubility or other surfacerelated processes as previously observed for the citric acid model system (Lienhard et al., 2014), in agreement with the 

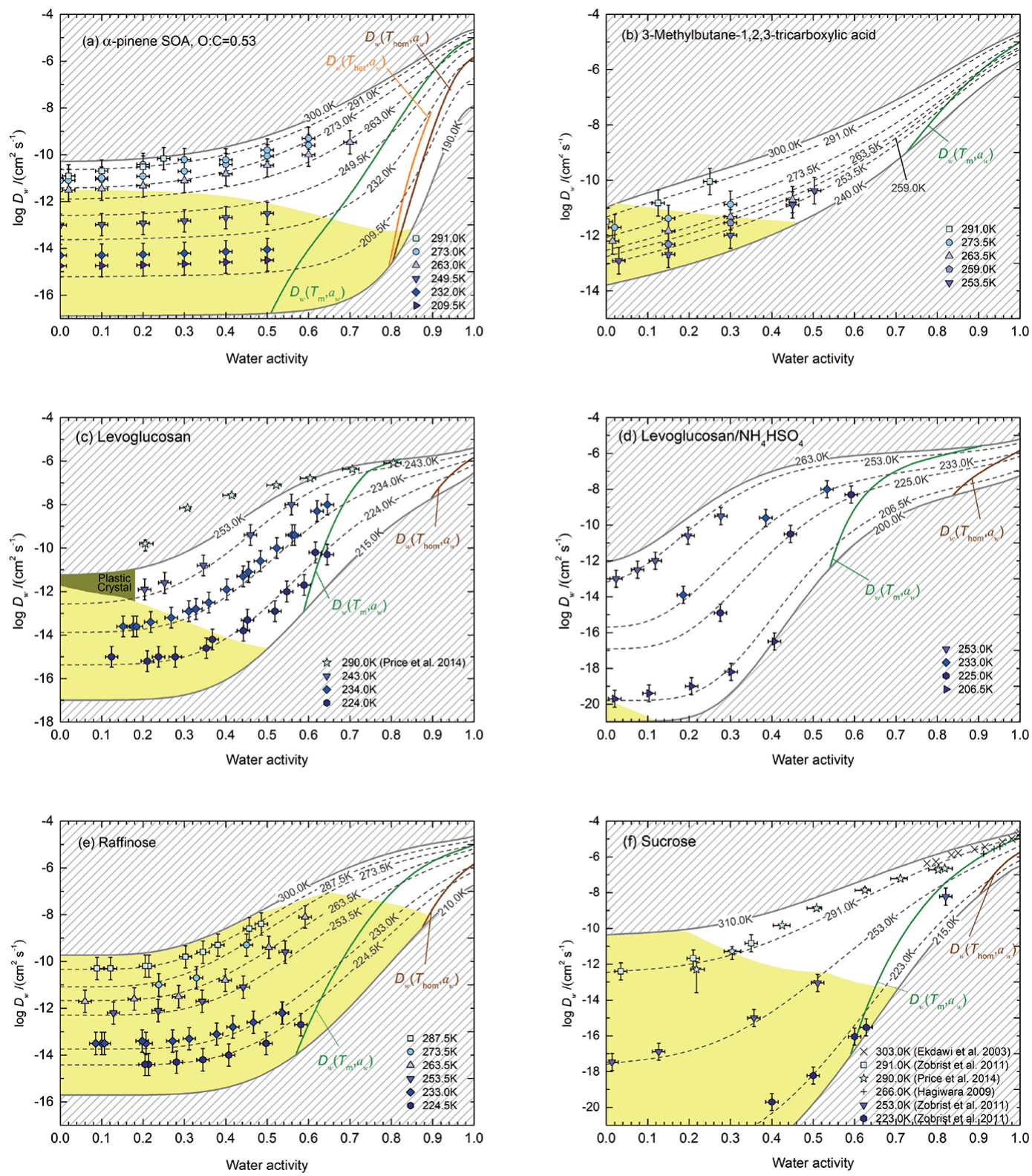

Figure 2. Water diffusion coefficients, $D_{\mathrm{w}}\left(T, a_{\mathrm{w}}\right)$, derived from kinetic response experiments shown together with the available data from the literature (Ekdawi-Sever et al., 2003; Hagiwara et al., 2009; Price et al., 2014). The color and shape of the data points indicate the temperature at which the data were obtained. The dashed lines are the temperature and composition dependent fits through all data points using the modified Vignes equation (see Appendix A). The fits were also used to calculate water diffusivity along the ice melting temperature, $D_{\mathrm{w}}\left(T_{\mathrm{m}}, a_{\mathrm{W}}\right)$, green lines, where $T_{\mathrm{m}}$ is calculated according to Murphy and Koop (2005) and along the homogeneous ice freezing temperature, $D_{\mathrm{w}}\left(T_{\mathrm{hom}}, a_{\mathrm{W}}\right)$, brown lines, where $T_{\mathrm{hom}}$ is calculated according to Koop et al. (2000) for a droplet of $100 \mathrm{~nm}$ radius and a homogeneous nucleation rate of $\omega=1 \mathrm{~min}^{-1}$. The orange line in panel (a) represents water diffusivity at conditions required for heterogeneous ice nucleation in SOA particles, $D_{\mathrm{w}}\left(T_{\text {het }}, a_{\mathrm{w}}\right)$, where $T_{\text {het }}$ is calculated according to Berkemeier et al. (2014). The yellow areas mark the regions where the mixtures are in the glassy state according to glass transition temperatures given in Appendix A. (a) $\alpha$ pinene SOA O : $\mathrm{C}=0.53, \mathrm{H}: \mathrm{C}=1.50$, (b) 3-methylbutane-1,2,3-tricarboxylic acid (3-MBTCA), $\mathrm{O}: \mathrm{C}=0.75, \mathrm{H}: \mathrm{C}=1.5$ (c) levoglucosan, $\mathrm{O}: \mathrm{C}=0.83, \mathrm{H}: \mathrm{C}=1.67$, (d) levoglucosan $/ \mathrm{NH}_{4} \mathrm{HSO}_{4}$ mixture with a dry molar ratio of $1: 1$, (e) raffinose, $\mathrm{O}: \mathrm{C}=0.89, \mathrm{H}: \mathrm{C}=1.78,(\mathbf{f})$ sucrose, $\mathrm{O}: \mathrm{C}=0.92, \mathrm{H}: \mathrm{C}=1.83$. Note that the range of temperatures for which measurements have been performed and the scales for the water diffusion coefficients vary between the different compounds. 
interpretation of Bateman et al. (2015). In addition, we suggest that the observations by Pajunoja et al. (2015) reflect the non-ideality of the solution mixture which is not accounted for by a single parameter representation for hygroscopic growth (see, e.g. Rickards et al., 2013).

Figure 2 shows results for five compounds not published previously together with the measurements for sucrose reported by Zobrist et al. (2011) which are based on experiments and diffusion model calculations as described above. The values of $D_{\mathrm{w}}$ at certain water activity intervals from one individual experiment were chosen to produce the temperature and concentration dependent fits shown in Fig. 2. For completeness, previously published results for other compounds are shown in Fig. A2 in Appendix A.

The experimentally determined water diffusion coefficients in these organic materials span about 12 orders of magnitude, from about $10^{-20} \mathrm{~cm}^{2} \mathrm{~s}^{-1}$ (sucrose: $a_{\mathrm{w}}=0.4, T=$ $223 \mathrm{~K}$ ) to about $10^{-8} \mathrm{~cm}^{2} \mathrm{~s}^{-1}$ (levoglucosan: $a_{\mathrm{w}}=0.55, T=$ $243 \mathrm{~K})$. Higher values of water diffusivity can not be measured because equilibration times become too short to be resolved within our experiments. At lower temperatures, ice formation in the chamber of the EDB limits the range of $\mathrm{RH}$ that can be investigated to conditions below ice saturation. However, it is possible to parametrize $D_{\mathrm{w}}\left(T, a_{\mathrm{w}}\right)$ over the entire two-dimensional concentration and temperature range in a self-consistent manner by constraining the fits at the two limiting cases of $a_{\mathrm{w}}=1$ and at $a_{\mathrm{w}}=0$. The diffusion coefficient of water in pure water, $D_{\mathrm{w}}(T, 1)$, is taken from Smith and Kay (1999) and the diffusion coefficient of water in the matrix of the pure organic compounds, $D_{\mathrm{w}}(T, 0)$, is considered an activated process and can thus be expressed by an Arrhenius equation. In between these constraints, we parametrize the modeled $D_{\mathrm{w}}\left(T, a_{\mathrm{w}}\right)$ over the entire range of $a_{\mathrm{w}}$ using a modified Vignes equation (Vignes, 1966, more details about the equations used and the fit parameters for the compounds are given in Appendix A).

The measured water diffusion coefficients for the different compounds are not trivially linked to their physicochemical properties. However, some general observations may be drawn from Fig. 2. First, the model shows that the dependence of water diffusion on water activity at different temperatures generally shows an "S-shape", which is reproduced by the empirical Vignes equation. Second, we find that water diffusivity is not easily correlated with the glass transition temperature. This is evident from the comparison between $D_{\mathrm{w}}(T, 0)$ of the mixture of ammonium bisulfate with levoglucosan and raffinose at about $253 \mathrm{~K}$. Although $T_{\mathrm{g}}$ of raffinose is about $170 \mathrm{~K}$ higher, water diffusion in pure raffinose is more than 1 order of magnitude faster than in the ammonium bisulfate and levoglucosan mixture.

In Fig. 3a we show water diffusivity extrapolated to dry conditions $\left(D_{\mathrm{w}}(T, 0)\right)$ for all measured compounds together with the diffusion coefficient of water in pure water $\left(D_{\mathrm{w}}(T, 1)\right)$. When extrapolated to $310 \mathrm{~K}$, the values for $D_{\mathrm{w}}(T, 0)$ seem to be of similar magnitude for all compounds.

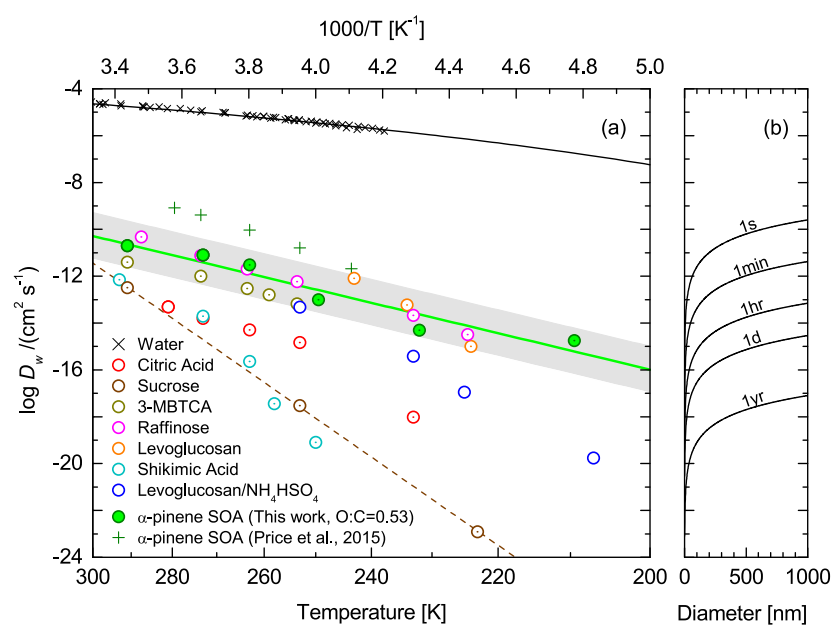

Figure 3. (a) Logarithm of the water diffusion coefficient in the pure component model mixtures, $D_{\mathrm{W}}(T, 0)$, from this and previous work (Zobrist et al., 2011; Lienhard et al., 2014; Steimer et al., 2015), displayed as a function of temperature (bottom scale) and inverse temperature (top scale). The green solid line and the brown dashed line are the parameterizations of $\alpha$-pinene SOA and sucrose, respectively. The light-gray shaded area marks a range of water diffusivity in the SOA extract \pm 1 order of magnitude. The solid black line represents the self-diffusion coefficient of water, $D_{\mathrm{W}}(T, 1)$, according to Smith and Kay (1999) with measurements indicated by black crosses (Pruppacher, 1972; Gillen et al., 1972; Price et al., 1999). Circles with a centered dot indicate that the data point is below the glass transition temperature. Water diffusivities in an $\alpha$ pinene SOM of unknown O : C ratio reported recently by Price et al. (2015) are shown for comparison. (b) Upper limits of equilibration times for particles of different sizes calculated by assuming that the diffusivity follows Fick's law according to Eq. (1).

At lower temperatures we find that the water diffusivity of 3-MBTCA, levoglucosan and raffinose behaves similarly to that of the SOA extract (within \pm 1 order of magnitude as indicated by the gray shaded area). Sucrose and shikimic acid, however, have a significantly stronger temperature dependence leading to differences in $D_{\mathrm{w}}(T, 0)$ of about ten orders of magnitude at temperatures typical for the upper troposphere. Citric acid and the mixture of levoglucosan and ammonium bisulfate fall in between the two groups mentioned above. At present we are not able to correlate these significant differences to any individual macroscopic physical property of the compounds. Based on these results we take the water diffusivity of the $\alpha$-pinene SOA extract (within \pm 1 order of magnitude) as being representative for water diffusivity in SOA. Clearly, further work is needed to prove that this choice is justified.

For comparison we also show in Fig. 3a the recent data of Price et al. (2015) who parametrized the water diffusion coefficient in $\alpha$-pinene SOM (of unspecified $\mathrm{O}: \mathrm{C}$ ratio) based on Raman isotope tracer experiments. Their water diffusion coefficients in the matrix of the $\alpha$-pinene SOM are about 2 
orders of magnitude larger than those we measured but show qualitatively the same temperature dependence. The difference could be due to the different material under investigation, but also due to systematic differences between the two experimental techniques. We believe our experimental method to infer water diffusivity is closely related to the atmospheric application as it is based on the response time to changes in RH but at present we cannot account for the differences between the two methods. However, those differences do not influence our conclusions on the atmospheric implications described and discussed below.

If we neglect the plasticizing effect of water, we can use the $D_{\mathrm{w}}(T, 0)$-values as lower limits for water diffusion in natural particles. This allows to estimate the absolute upper limit for the atmospheric equilibration times $\left(\tau_{\mathrm{aq}}\right)$ for organic aerosols using the characteristic time for aqueous phase diffusion of a tracer (Seinfeld and Pandis, 1998):

$$
\tau_{\mathrm{aq}}=\frac{d_{\mathrm{p}}^{2}}{4 \pi^{2} D_{\mathrm{w}}\left(T, a_{\mathrm{w}}\right)} \leq \frac{d_{\mathrm{p}}^{2}}{4 \pi^{2} D_{\mathrm{w}}(T, 0)} .
$$

Figure $3 \mathrm{~b}$ shows upper limits of these equilibration times vs. particle diameter, $d_{\mathrm{p}}$. For water diffusion constants in the gray shaded area (panel a) this implies equilibration times for large accumulation size particles of about $1 \mathrm{~s}$ at room temperature and up to several hours at $200 \mathrm{~K}$. However, equilibration times for realistic atmospheric water uptake scenarios may be significantly shorter when the plasticizing effect of water is taken into account, as will be discussed in Sect. 4.

\section{Atmospheric implications}

Our previous measurements showed that sucrose particles may become glassy under cold, dry conditions, resulting in drastic limitations of water uptake and particle growth, with potential repercussions for ice nucleation and heterogeneous chemistry (Zobrist et al., 2011). To the degree that sucrose particles could be considered suitable proxies for organic particles in the natural atmosphere, the same internal transport limitations would apply to atmospheric aerosols. However, here we show that water diffusion in particles with compositions that are more representative of natural particles is much higher than in previously investigated proxies such as sucrose particles. Our new measurements suggest that water diffusivity does not hinder water uptake by atmospheric organic aerosols under most tropospheric conditions, and that water diffusivity in organic particles is faster than recently assumed by Berkemeier et al. (2014) and Arangio et al. (2015), but lower than measured by Price et al. (2015). Our results also suggest that SOA particles are most likely equilibrated with the surrounding relative humidity even when measurements of bounce factors or viscosities imply that the particles are in the amorphous solid state (Virtanen et al., 2010; Renbaum-Wolff et al., 2013).
We simulated two scenarios representative of prevailing cloud types in order to explore the effect of water diffusion on cloud activation by accumulation size particles with typical radii of $100 \mathrm{~nm}$ : upper tropospheric clouds in the mid-latitudes (Fig. 4) and very high clouds near the tropical tropopause (Fig. 5). The trajectory of the first scenario, shown in Fig. 4a, starts at $40 \% \mathrm{RH}$ and $220 \mathrm{~K}$ and reaches conditions close to water saturation through typical adiabatic updrafts of $0.1 \mathrm{~ms}^{-1}$, characteristic for ubiquitous smallscale temperature fluctuations and 1 and $3 \mathrm{~m} \mathrm{~s}^{-1}$ for convectively more perturbed conditions. Panel (b) of Fig. 4 indicates that the particle radius in these simulations never deviates by more than $8 \%$ from the equilibrium radius upon the formation of upper tropospheric clouds in the mid-latitudes, even when fast updrafts are assumed. These deviations from equilibrium stem from the liquid-phase impedance, while gas-phase diffusion is rapid for particles with radii of about $100 \mathrm{~nm}$. The deviation for the simulation with the fastest updraft increases to about $10 \%$ when the diffusion of water in pure SOA is assumed to be 1 order or magnitude smaller (corresponding to the lower limit of the gray shaded area in Fig. 3) and decreases to about $5 \%$ for 1 order of magnitude faster diffusion (corresponding to the upper limit of the gray shaded area of Fig. 3), which provides an estimation for the uncertainties in our simulations.

Figure 4 also shows the water concentration profile of the droplets upon reaching (d) ice saturation, (e) conditions required for heterogeneous ice nucleation according to the estimates of Berkemeier et al. (2014) and (f) conditions required for homogeneous ice nucleation according to Koop et al. (2000) (i.e. the homogeneous nucleation rate $\omega=1 \mathrm{~min}^{-1}$ for an equilibrated droplet of $100 \mathrm{~nm}$ radius). The model results for cirrus cloud conditions demonstrate that SOA particles might still be glassy when reaching ice saturation, but they establish a liquid shell when reaching conditions required for heterogeneous ice nucleation or will even be entirely equilibrated under slow updraft velocities. Hence heterogeneous ice nucleation may only be possible for medium to fast updraft velocities where the droplets still contain a highly viscous core. When homogeneous ice nucleation conditions are reached, only the droplets undergoing fast updrafts still contain a small viscous core, but the liquid shell is well equilibrated. Thus, the homogeneous ice nucleation rates shown in panel (c) for all updraft velocities coincide with the rate coefficient of a droplet with no condensedphase limitations for all updraft velocities (red, orange and green lines coincide with the black dotted line). In this study, we calculate $\omega$ according to Koop et al. (2000) and assume that ice nucleation occurs only when the thickness of the diluted layer is equal to or larger than the diameter of the critical ice nuclei. A simulation starting at $228 \mathrm{~K}$ provided as Fig. A1 in the Appendix shows that for these slightly warmer conditions, condensed-phase diffusion in SOA particles is fast enough to have no influence on ice nucleation. This means in effect that $220 \mathrm{~K}$ is the highest temperature at 


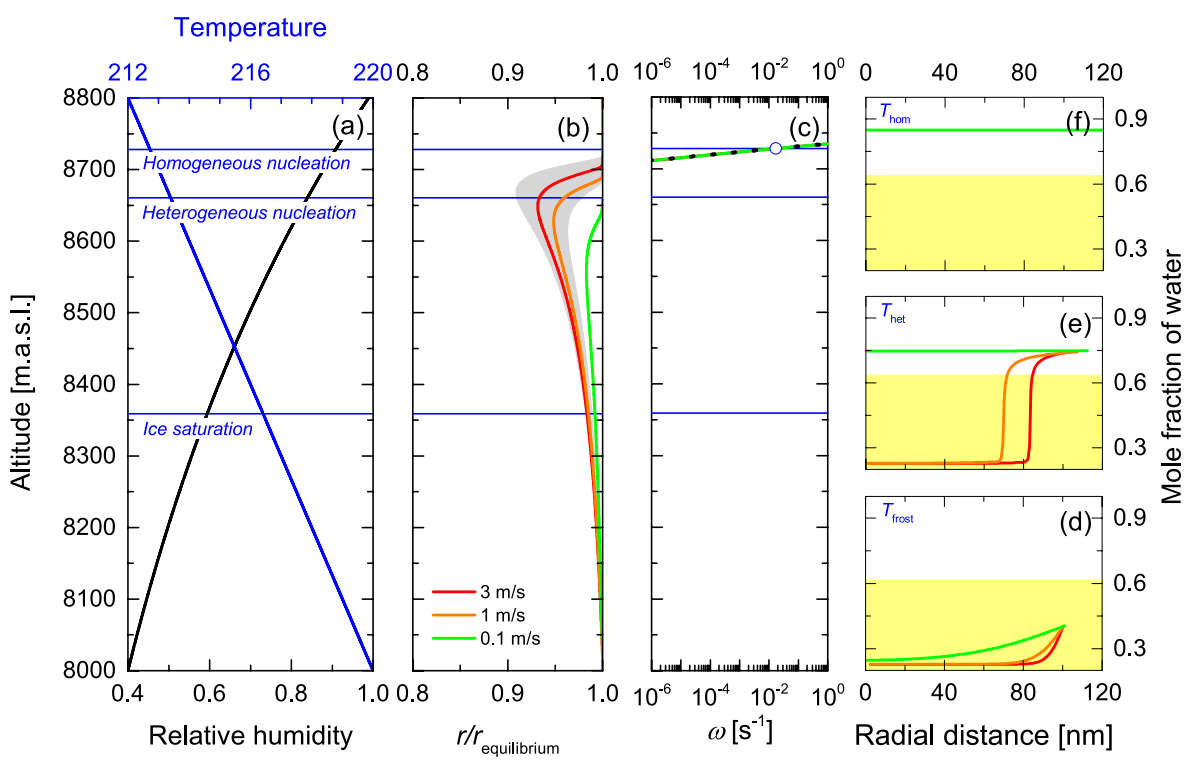

Figure 4. Simulation of secondary organic aerosol particles with an initial radius of $100 \mathrm{~nm}$ in an air parcel experiencing adiabatic updraft conditions typical of the upper troposphere in mid-latitudes below $220 \mathrm{~K}$. (a) Air parcel temperature (blue line, top scale) and relative humidity (black line, bottom scale). (b) Ratio of modeled radius over thermodynamic equilibrium radius when experiencing 0.1 (green line), 1 (orange line) and $3 \mathrm{~m} \mathrm{~s}^{-1}$ (red line) linear updraft velocities. The gray shaded area indicates the effect of \pm 1 order of magnitude difference in the water diffusivity in the pure $\alpha$-pinene SOA for an updraft velocity of $3 \mathrm{~m} \mathrm{~s}^{-1}$ (see also gray shaded area in Fig. 3). (c) Homogeneous ice nucleation rates, $\omega$, in the current case overlapping with each other and with equilibrium conditions (black dashed line). Also shown are the water concentration profiles upon reaching $(\mathbf{d})$ ice saturation at the frost point, $T_{\text {frost }}$, (e) heterogeneous ice nucleation conditions typical for SOA particles (Berkemeier et al., 2014), and (f) homogeneous ice nucleation conditions, i.e. the altitude where the black dotted line in panel (c) is equal to $1 \mathrm{~min}^{-1}$, marked by the blue circle. Since the particles are well equilibrated under these conditions for all updraft velocities, the concentration profiles in panel (f) overlap with each other. The yellow areas indicate the concentrations at which the mixtures are in the glassy state.

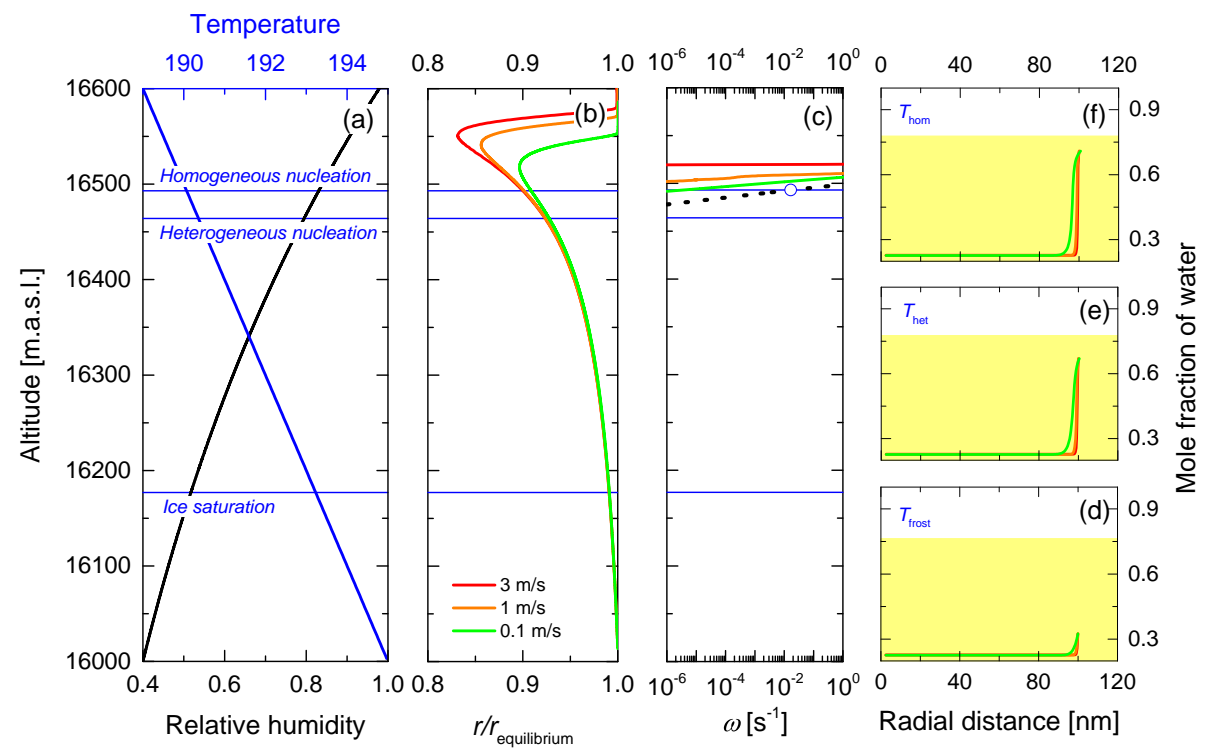

Figure 5. Same as Fig. 4 but for organic aerosol particles experiencing adiabatic updrafts under conditions typical of the very high upper troposphere in the tropics, starting at $40 \% \mathrm{RH}$ and $195 \mathrm{~K}$ with linear updraft velocities of $0.1,1$ and $3 \mathrm{~m} \mathrm{~s}^{-1}$. In (c) the homogeneous freezing temperatures are lowered by $0.10 \mathrm{~K}$ for $0.1 \mathrm{~m} \mathrm{~s}^{-1}$ updraft velocity and $0.28 \mathrm{~K}_{\text {for }} 3 \mathrm{~m} \mathrm{~s}^{-1}$ updraft velocity. 
which condensed-phase diffusion influences ice nucleation for SOA particles with water diffusion coefficients as the ones shown in Fig. 2a.

In the second scenario, simulating very high convective clouds near the tropical tropopause in Fig. 5, the droplets show delayed homogeneous ice nucleation for all updraft velocities. Condensed-phase diffusion is slow enough such that homogeneous ice nucleation occurs only about $50 \mathrm{~m}$ (or about $5 \% \mathrm{RH}$ ) higher than expected, because of the slow formation of liquid layers. Heterogeneous ice nucleation prior to homogeneous nucleation may only occur via the deposition mode as the droplets only consist of glassy layers, in agreement with the observations of Wang et al. who used naphthalene as precursor for SOA (Wang et al., 2012). The results in Fig. 5 show that even for these extreme conditions, the radii of the droplets never deviate by more than about $18 \%$ from the equilibrium radius. Hence we believe that water diffusivity in SOA particles is sufficiently fast under realistic atmospheric water uptake scenarios such that global models can treat these particles as if they are in equilibrium with the surrounding relative humidity. The direct climatic effects of SOA particles, i.e. their scattering and absorptive properties, are thus unlikely to be significantly affected by condensedphase water diffusivity.

\section{Conclusions}

Water diffusivity in organic aerosol particles does not strictly correlate with the glass transition temperature and is not trivially linked to physicochemical properties but may vary by several orders of magnitude between the different model systems investigated in this study. Our measurements suggest that water diffusion coefficients in secondary organic material are sufficiently high such that SOA particles can be considered as equilibrated with the surrounding water vapor at temperatures above $220 \mathrm{~K}$, even when the particles are in the amorphous solid state.

The model simulations of realistic atmospheric water uptake scenarios in the upper troposphere show that homogeneous ice nucleation is only suppressed for a short period of time for the model runs starting at $195 \mathrm{~K}$, i.e. under conditions found only near the tropical tropopause. For all other conditions in the troposphere, homogeneous ice nucleation rates are unaffected by condensed-phase water diffusion. SOA particles undergoing fast convective updrafts at temperatures below $220 \mathrm{~K}$ may still contain a glassy core when conditions required for homogeneous ice nucleation are reached. Hence ice may freeze heterogeneously on this glassy core before reaching the homogeneous nucleation threshold. Under the very cold conditions near the tropical tropopause, heterogeneous ice nucleation can only occur via deposition freezing because the hydrated outer layers of the particles are still in the glassy state at the homogeneous nucleation threshold.

The measurements and simulations presented in this study show that water diffusion in SOA particles affects ice nucleation rates and results in deviations from equilibrium growth only under conditions found in the upper troposphere. Condensed-phase water diffusivity is thus unlikely to significantly influence the direct climatic effects of SOA particles under tropospheric conditions. 


\section{Appendix A}

\section{A1 Model calculation at $228 \mathrm{~K}$}

Figure A1 shows a simulation of SOA droplets experiencing updraft velocities of $0.1,1$ and $3 \mathrm{~m} \mathrm{~s}^{-1}$ starting at $40 \% \mathrm{RH}$ and $228 \mathrm{~K}$, slightly warmer than the conditions outlined in Fig. 4 in the main text. The calculations indicate that water diffusion at these temperatures is fast enough for complete equilibration with the gas phase before the conditions required for heterogeneous nucleation are reached. The simulated radius deviates by no more than $5 \%$ from the equilibrium radius.

\section{A2 Parameterization of $D_{\mathrm{w}}\left(T, a_{\mathrm{w}}\right)$}

Figures A2 and 2 show all measurements of water diffusivity from this study and our previous work in levitated particles at temperatures between 206.5 and $291.0 \mathrm{~K}$, covering a large range of atmospherically relevant temperatures, together with the available data from the literature (EkdawiSever et al., 2003; Hagiwara et al., 2009; Zobrist et al., 2011; Price et al., 2014; Lienhard et al., 2014; Steimer et al., 2015). These data show that water diffusivity strongly depends on temperature and concentration. The diffusion coefficient of water in pure water, $D_{\mathrm{w}}(T, 1)$, and the diffusion coefficient of water in a pure matrix of larger molecules, $D_{\mathrm{w}}(T, 0)$, have been subject to a number of investigations (Park, 1986). Their temperature dependence is typically expressed by the Arrhenius equation if diffusion is treated as an activated process or by the Vogel-Fulcher-Tammann (VFT) equation as implied by the free-volume theory (Cohen and Grest, 1979; Hong, 1995; Debenedetti and Stillinger, 2001). These equations have the form

$D_{\mathrm{w}}\left(T, a_{\mathrm{w}}\right) /\left(\mathrm{cm}^{2} \mathrm{~s}^{-1}\right)=\exp (\zeta)$,

where for the Arrhenius equation $\left(\zeta=\zeta_{\mathrm{A}}\right)$

$\zeta_{\mathrm{A}}=\zeta_{\mathrm{A}}^{\mathrm{o}}-\frac{E_{\mathrm{act}}}{R T}$,

and for the VFT equation $\left(\zeta=\zeta_{\mathrm{V}}\right)$

$\zeta_{\mathrm{V}}=\zeta_{\mathrm{V}}^{\mathrm{o}}-\frac{S}{T-T_{\mathrm{O}}}$

$R$ denotes the gas constant, $E_{\text {act }}$ is the activation energy and $\zeta_{\mathrm{A}}^{\mathrm{o}}, \zeta_{\mathrm{V}}^{\mathrm{o}}, S$ and $T_{\mathrm{o}}$ are fit parameters. In this work, we apply the VFT equation for $D_{\mathrm{w}}(T, 1)$ using the values found by Smith and Kay (1999) which covers the atmospherically relevant temperature range while the Arrhenius equation represents $D_{\mathrm{w}}(T, 0)$ reasonably well for all model systems. For SOA particles, we found an activation energy of about $65 \mathrm{~kJ} \mathrm{~mol}^{-1}$. This value is in the same range as other $E_{\text {act }}$ reported in the literature, e.g. $16 \mathrm{~kJ} \mathrm{~mol}^{-1}$ in hydrocarbons (298 to $317 \mathrm{~K}), 60 \mathrm{~kJ} \mathrm{~mol}^{-1}$ in carbohydrates (285 to $345 \mathrm{~K}$ ) and between 10 and $80 \mathrm{~kJ} \mathrm{~mol}^{-1}$ in polymers ( 293 to $359 \mathrm{~K}$ ) (Kokes and Long, 1953; Long and Thompson, 1955; Kumins et al., 1957; Yasuda and Stannett, 1962; Schatzberg, 1965; Hardy, 1967; Demertzis and Kontominas, 1989; Tromp et al., 1997). Table A1 lists the activation energies of our other model systems, which in general are slightly higher than those reported in the literature.

For the limited temperature range investigated in this work $E_{\text {act }}$ is assumed to be independent of temperature. Strictly speaking, $E_{\text {act }}$ might change at $T_{\mathrm{g}}$ of the matrix and is also a function of temperature above $T_{\mathrm{g}}$, thus complicating the interpretation of this value as an Arrhenius activation energy (Kumins and Roteman, 1961; Launay et al., 1999; Cai et al., 2002). Since our measurements are either mostly below or mostly above the $T_{\mathrm{g}}$ of the respective matrix, we relate $\zeta_{\mathrm{A}}^{\mathrm{o}}$ to $T_{\mathrm{g}}$ according to

$\zeta_{\mathrm{A}}^{\mathrm{o}}=\ln \left[D_{\mathrm{w}}\left(T_{\mathrm{g}}, 0\right) /\left(\mathrm{cm}^{2} \mathrm{~s}^{-1}\right)\right]+\frac{E_{\mathrm{act}}}{R T_{\mathrm{g}}}$,

where $D_{\mathrm{w}}\left(T_{\mathrm{g}}, 0\right)$ is the water diffusion coefficient at the glass transition of the matrix. The values for $\ln \left[D_{\mathrm{w}}\left(T_{\mathrm{g}}, 0\right) /\left(\mathrm{cm}^{2} \mathrm{~s}^{-1}\right)\right]$ and $T_{\mathrm{g}}$ are listed in Table A1 and shown in Fig. A3 to illustrate the wide range of water diffusivities at the glass transition temperatures of the model mixtures.

A number of models exist to describe the concentration dependence of water diffusivities in mixtures. Of these, only molecular dynamics simulations and the free-volume theory explicitly address the transition from a liquid or rubbery system to a glass as the concentration is varied (Vrentas et al., 1988; Vrentas and Vrentas, 1994, 2003; Ramesh et al., 2011). A validation of these two models with the data presented here is beyond the scope of this work since many material properties needed to simulate $D_{\mathrm{w}}\left(T, a_{\mathrm{w}}\right)$ are unknown. However the free-volume theory qualitatively predicts an "S-shaped" curve when the system turns into a glass, in agreement with our observations in Figs. 2 and A2 (Vrentas et al., 1988; Vrentas and Vrentas, 1994, 2003; Ramesh et al., 2011). This concentration dependence is interpreted as a change in the redistribution of free volume from the large coordinated motion of the matrix molecule ( $\alpha$-relaxation) above $T_{\mathrm{g}}$ to the opening and closing of voids by faster processes ( $\beta$-relaxation, see Ramesh et al., 2011).

The glassy regions in Figs. 2 and A2 refer to a condition where the heat capacity of the system is markedly lower than in the liquid state owing to the loss of configurational degrees of freedom, typically measured with differential scanning calorimetry (DSC). The composition at which the system turns into a glass according to this interpretation differs from the composition where the water diffusivity shows a rapid change. This behavior, also observed in non-aqueous polymer systems, can be explained in terms of the different properties being investigated (Faldi et al., 1994; Tonge and Gilbert, 2001; Karlsson et al., 2001). $D_{\mathrm{w}}\left(T, a_{\mathrm{w}}\right)$ represents a property that describes a rate of transport and ultimately 


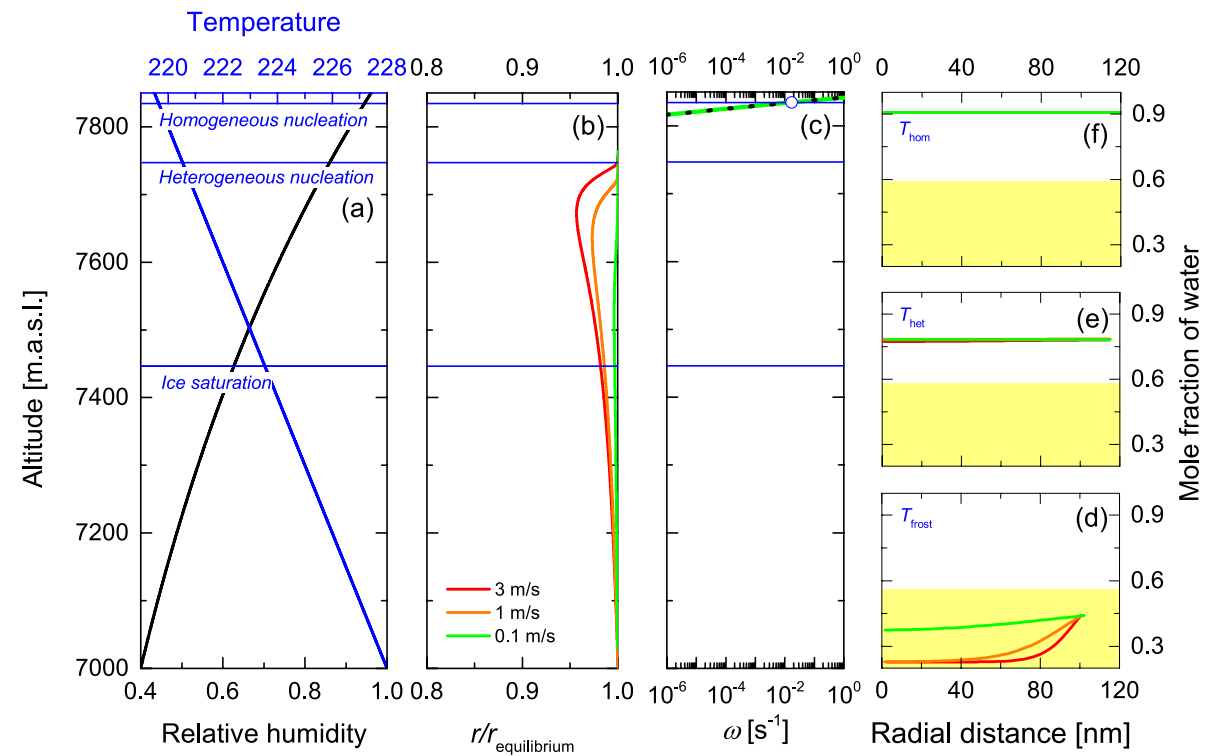

Figure A1. Same as Fig. 4 in the main text but for organic aerosol particles experiencing adiabatic updrafts starting at $40 \%$ RH and $228 \mathrm{~K}$ with linear updraft velocities of $0.1,1$ and $3 \mathrm{~ms}^{-1}$.

Table A1. Fit parameters for Eqs. (A4) and (A6) .

\begin{tabular}{|c|c|c|c|c|c|c|c|c|c|c|}
\hline Mixture & $\begin{array}{r}\ln \left[D_{\mathrm{W}}\left(T_{\mathrm{g}}, 0\right)\right. \\
\left./\left(\mathrm{cm}^{2} \mathrm{~s}^{-1}\right)\right]\end{array}$ & $\begin{array}{r}E_{\text {act }} \\
{\left[\mathrm{kJ} \mathrm{mol}^{-1}\right]}\end{array}$ & $\begin{array}{r}T \text { range } \\
{[\mathrm{K}]}\end{array}$ & $\begin{array}{r}T_{\mathrm{g}} \\
{[\mathrm{K}]}\end{array}$ & $a_{1}$ & $\begin{array}{r}a_{2} \\
{\left[\mathrm{~K}^{-1}\right]}\end{array}$ & $\begin{array}{r}T_{a} \\
{[\mathrm{~K}]}\end{array}$ & $b_{1}$ & $\begin{array}{r}b_{2} \\
{\left[\mathrm{~K}^{-1}\right]}\end{array}$ & $\begin{array}{r}T_{b} \\
{[\mathrm{~K}]}\end{array}$ \\
\hline Levoglucosan & -27.06 & 157.9 & $215-253$ & $249.0^{\mathrm{d}}$ & -52.77 & 0.211 & 243.0 & 8.561 & 0.027 & 243.0 \\
\hline $\begin{array}{l}\text { Levoglucosan/ } \\
\mathrm{NH}_{4} \mathrm{HSO}_{4}\end{array}$ & -45.58 & 142.2 & $200-263$ & $206.5^{\mathrm{e}}$ & -44.96 & 0.185 & 243.0 & 16.57 & -0.063 & 243.0 \\
\hline Raffinose & -15.76 & 80.1 & $210-300$ & $378.3^{f}$ & -139.9 & 0.347 & 273.5 & 17.00 & 0.00 & 273.5 \\
\hline 3-МBTCA & -24.86 & 64.5 & $240-300$ & $305.0^{\mathrm{g}}$ & -5.033 & 0.015 & 300.0 & 0.00 & 0.00 & 300.0 \\
\hline$\alpha$-pinene $\mathrm{SOA}^{\mathrm{b}}$ & -26.60 & 65.5 & $190-300$ & $270.0^{\mathrm{h}}$ & -18.31 & 0.063 & 273.0 & -10.65 & 0.039 & 273.0 \\
\hline Sucrose $^{c}$ & -18.22 & 190.3 & $215-310$ & $335.7^{\mathrm{i}}$ & -16.65 & 0.050 & 253.0 & -14.65 & 0.050 & 253.0 \\
\hline Citric Acid ${ }^{\mathrm{c}}$ & -29.67 & 122.3 & $223-290$ & $280.1^{\mathrm{e}}$ & -41.00 & 0.143 & 265.0 & -69.00 & 0.280 & 255.0 \\
\hline Shikimic Acid ${ }^{\mathrm{c}}$ & -18.21 & 204.9 & $240-300$ & $326.8^{j}$ & -16.30 & 0.062 & 263.0 & 16.30 & -0.062 & 263.0 \\
\hline
\end{tabular}

a with $A(T)=a_{1}+a_{2} T$ for $T \leq T_{a}$ and $A(T)=A\left(T_{a}\right)$ for $T>T_{a}$, and $B(T)=b_{1}+b_{2} T$ for $T \leq T_{b}$ and $B(T)=B\left(T_{b}\right)$ for $T>T_{b}$. The temperature range for the parameterization is indicated.

$\mathrm{b}$ The molar mass of SOM is assumed to be $150 \mathrm{~g}$ for this parameterization. This value is only needed for the fit equation but does not influence the measurements of the concentration dependent diffusion coefficients as it is not needed to describe the thermodynamic and optical properties in Eqs. (A9) to (A11).

${ }^{c}$ The parameterization of $D_{\mathrm{w}}\left(T, a_{\mathrm{W}}\right)$ is based on literature data and measurements in our previous work (Ekdawi-Sever et al., 2003; Hagiwara et al., 2009; Zobrist et al., 2011; Price et al., 2014; Lienhard et al., 2014; Steimer et al., 2015).

${ }^{\mathrm{d}}$ From Lienhard et al. (2012a).

e Based on a Gordon-Taylor fit (Gordon and Taylor, 1952) between $T_{\mathrm{g}}$ of levoglucosan and $T_{\mathrm{g}}$ of $\mathrm{NH}_{4} \mathrm{HSO}_{4}$ taken from Zobrist et al. (2008).

${ }^{\mathrm{f}}$ From Lienhard et al. (2012b).

g From Dette et al. (2014).

$\mathrm{h}$ As estimated by Koop et al. (2011). In this study, we assume a Gordon-Taylor constant of 3.5 .

${ }^{i}$ From Zobrist et al. (2008).

$\mathrm{j}$ We estimated the Gorden-Taylor constant to be 2.32 based on the change in heat capacity at $T_{\mathrm{g}}$.

depends on the history of the formation of the material while $T_{\mathrm{g}}$ obtained from DSC measurements is governed by near-equilibrium micro-structures (Duda, 1985; Tonge et al., 2000).

In order to find a simple parameterization for $D_{\mathrm{w}}\left(T, a_{\mathrm{w}}\right)$ between the Arrhenius equation for $D_{\mathrm{w}}(T, 0)$ and the VFT equation for $D_{\mathrm{w}}(T, 1)$ we apply the linear relationship

$$
\zeta=\zeta_{\mathrm{A}}+x_{\mathrm{w}} \alpha\left(\zeta_{\mathrm{VFT}}-\zeta_{\mathrm{A}}\right),
$$

where $x_{\mathrm{w}}$ is the water mole fraction and $\alpha$ satisfies the Duhem-Margules relation (McGlashan, 1963): 

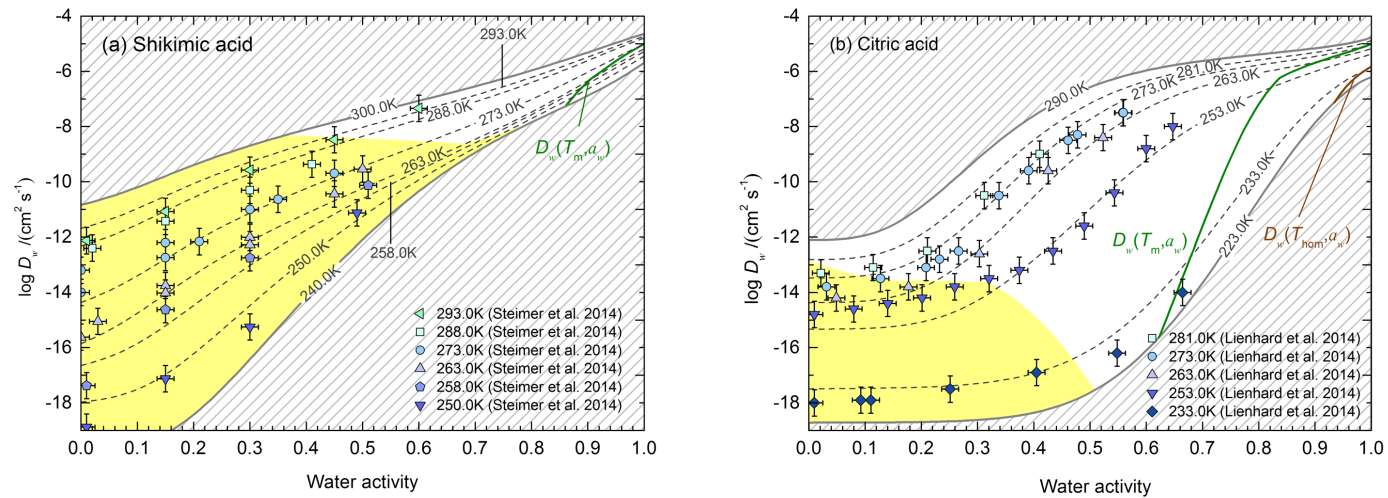

Figure A2. Same as Fig. 2 in the main text but for the previously measured model mixtures of (a) shikimic acid, $\mathrm{O}: \mathrm{C}=0.71, \mathrm{H}: \mathrm{C}=1.43$ and (b) citric acid, $\mathrm{O}: \mathrm{C}=1.17, \mathrm{H}: \mathrm{C}=1.33$.

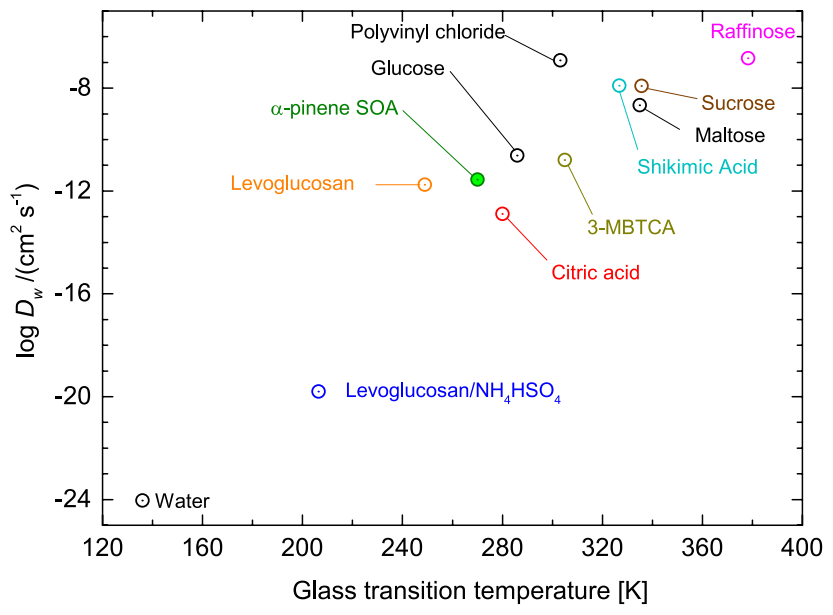

Figure A3. Water diffusivity at the glass transition temperatures of the pure component model mixtures, $D_{\mathrm{W}}\left(T_{\mathrm{g}}, 0\right)$, and at the glass transition of water, $D_{\mathrm{W}}\left(T_{\mathrm{g}}, 1\right)$, according to Smith and Kay (1999). Also shown are data from the literature for glucose, maltose and polyvinyl chloride (Kumins and Roteman, 1961; Parker and Ring, 1995). The values for shikimic acid, sucrose and raffinose are extrapolations of the parameterizations given in Table A1.

$\ln (\alpha)=\left(1-x_{\mathrm{w}}\right)^{2}\left[A(T)+3 B(T)-4 B(T) \cdot\left(1-x_{\mathrm{w}}\right)\right]$,

corresponding to a modified Vignes equation (Vignes, 1966; Lienhard et al., 2014),

$D_{\mathrm{w}}\left(T, a_{\mathrm{w}}\right)=D_{\mathrm{w}}(T, 0)^{1-x_{\mathrm{w}} \alpha} D_{\mathrm{w}}(T, 1)^{x_{\mathrm{w}} \alpha}$,

which represents all our model systems reasonably well. The parameters $A$ and $B$ are temperature dependent and described in Table A1 for all investigated systems.

The "S-shaped" percolation equation as suggested by Shiraiwa et al. (2013) was not considered because the underlying physical process does not allow for droplet growth or shrinkage over the entire range of relative humidities.

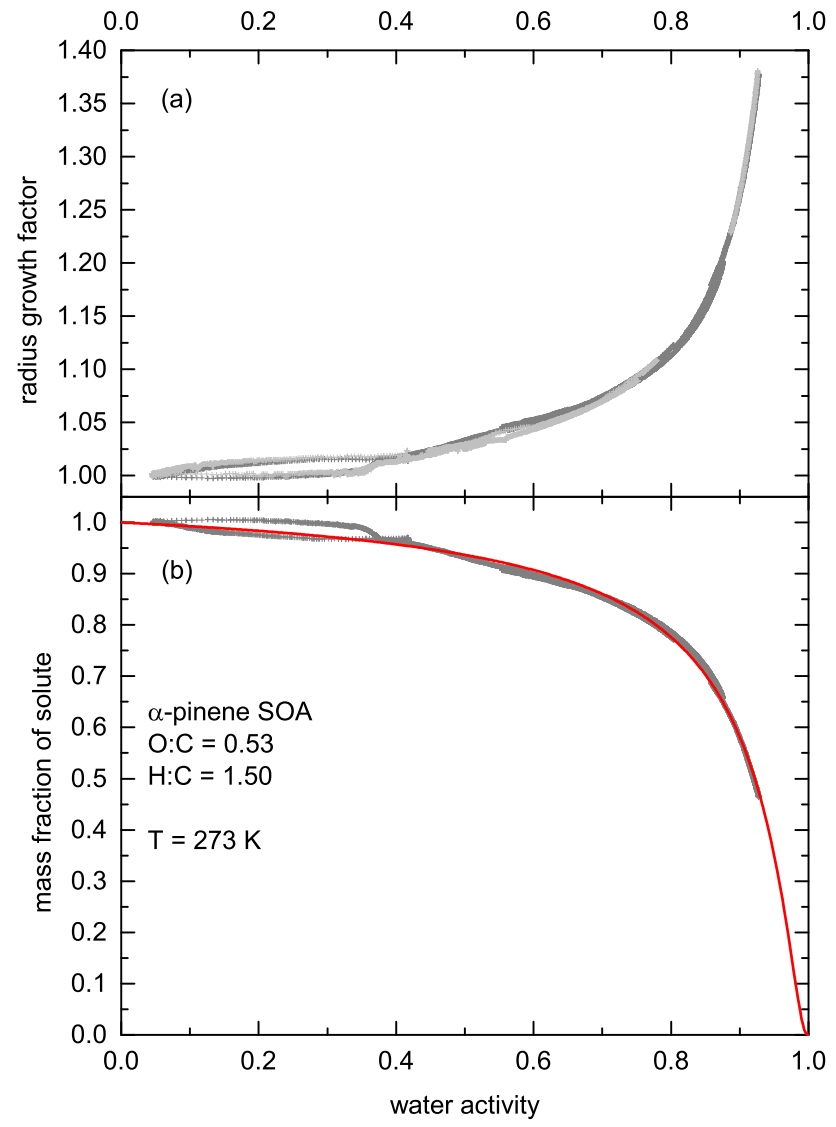

Figure A4. (a) Radius growth factor of a $\alpha$-pinene SOA particle $(\mathrm{O}: \mathrm{C}=0.53)$ at $273 \mathrm{~K}$ as derived from Mie resonance spectroscopy (light-gray crosses) and from mass balance (dark gray crosses) yielding $1.40 \pm 0.05 \mathrm{~g} \mathrm{~cm}^{-3}$ for the density of the pure solute. (b) Mass fraction of solute vs. water activity calculated from the data of panel (a). The red line represents the fit according to Eq. (A9). (A fit to a single parameter, $\kappa$, for describing hygroscopic growth as in Pajunoja et al. (2015) yields a value of $0.081 \pm 0.005$ Petters and Kreidenweis, 2007). 


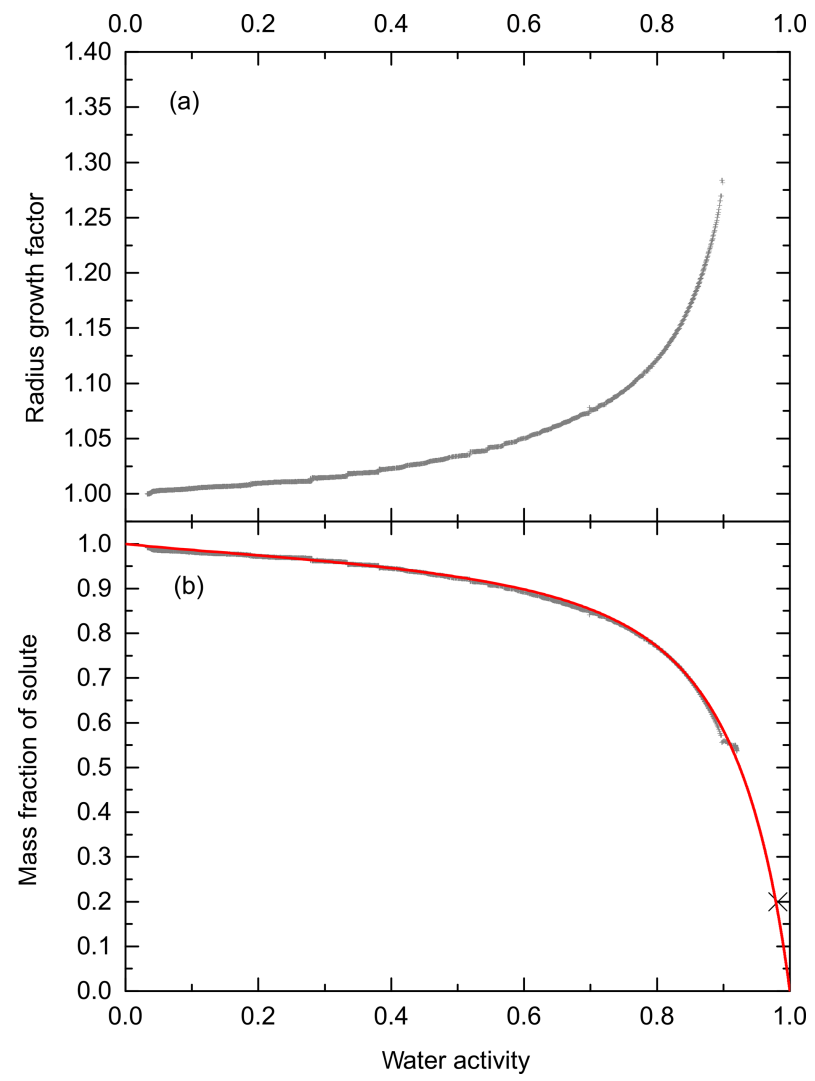

Figure A5. (a) Radius growth factor of a 3-MBTCA particle at $290 \mathrm{~K}$ as derived from Mie resonance spectroscopy (light-gray crosses) and from mass balance (dark gray crosses) using $1.428 \pm$ $0.05 \mathrm{~g} \mathrm{~cm}^{-3}$ for the density of the pure solute to convert from mass to size. (b) Mass fraction of solute vs. water activity calculated from the data of panel (a). The black cross represents a dew point measurement of a bulk solution. The red line represents the fit according to Eq. (A12).

\section{A3 Thermodynamic and optical properties}

The thermodynamic and optical properties needed for the model calculations are taken from Lienhard et al. (2012a) for raffinose, levoglucosan and the levoglucosan mixture with $\mathrm{NH}_{4} \mathrm{HSO}_{4}$. For the water activity parameterization of raffinose, which is not given by Lienhard et al. (2012a), we use

$a_{\mathrm{w}}=x_{\mathrm{w}} \exp \left(\left(1-x_{\mathrm{w}}\right)^{2}\left(-7.359+1.805\left(1-x_{\mathrm{w}}\right)\right)\right)$.

We used the procedure described in detail by Steimer et al. (2015) to determine density, refractive index and water activity of 3-MBTCA and the SOA extract. Growth curves of the SOA particles were measured at $273 \mathrm{~K}$ while illuminating the particle only with the tunable diode laser between 765 and $781 \mathrm{~nm}$ to prevent photochemical reactions. The changes in mass and size were measured simultaneously. The results for 3-MBTCA and SOA particles are shown in Figs. A4 and A5. The independent measurements of mass and size change agree over the entire range of relative humidity. The

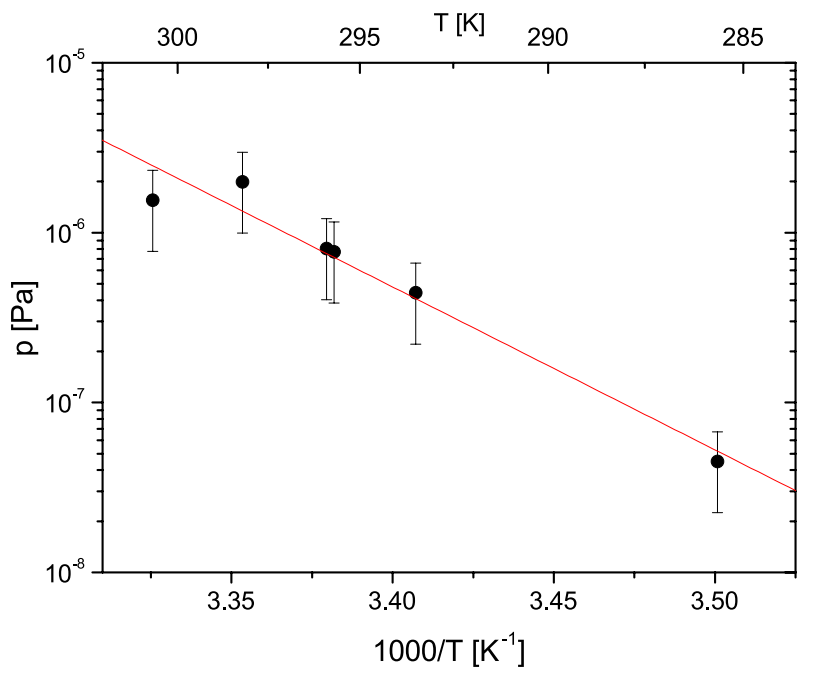

Figure A6. Vapor pressure of 3-MBTCA as function of inverse temperature (bottom scale) and temperature (top scale). An Arrhenius fit (red line) yields a vapor pressure at $298.15 \mathrm{~K}$ of $(1.4 \pm 0.5) \times$ $10^{-6} \mathrm{~Pa}$.

small hysteresis loop seen at relative humidities below $35 \%$ in Fig. A4 is related to kinetic limitations to water uptake and release which is used to derive water diffusivity. For the water activity, density $(\rho)$ and refractive index $(n)$ of the $\alpha$ pinene SOA mixtures with water used in this study we found as a function of mass fraction of solute ( $\mathrm{mfs})$ :

$a_{\mathrm{w}}=\frac{1-\mathrm{mfs}}{1-0.85848 \mathrm{mfs}-0.09026 \mathrm{mfs}^{2}}$,
$\rho=0.9989+0.27352 \mathrm{mfs}+0.12477 \mathrm{mfs}^{2}+0.00381 \frac{298-T}{298}$,

$n(589 \mathrm{~nm})=1.33266+0.19104 \rho \mathrm{mfs}$.

For 3-MBTCA mixtures with water we found

$a_{\mathrm{W}}=x_{\mathrm{W}} \exp \left(\left(1-x_{\mathrm{W}}\right)^{2}\left(1.09979-1.7392\left(1-x_{\mathrm{w}}\right)\right)\right.$,
$\rho=\frac{18 x_{\mathrm{W}}+204\left(1-x_{\mathrm{W}}\right)}{18 x_{\mathrm{W}}+142.9\left(1-x_{\mathrm{W}}\right)}$,
$n(589 \mathrm{~nm})=1.33243+0.02593 M$,

where $M$ is the molarity.

We also performed vapor pressure measurements for 3MBTCA as shown in Fig. A6 as described by (Zardini et al., 2006). These show that typical vapor pressures at temperatures below $290 \mathrm{~K}$ are at most $10^{-7} \mathrm{~Pa}$, corresponding to

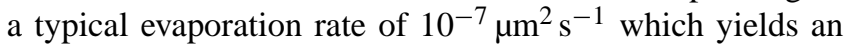
evaporative change in size of a particle with $8 \mu \mathrm{m}$ radius of less than $40 \mathrm{~nm}$ in 5 days. The evaporational loss of the $\alpha$ pinene SOA particles was similar in magnitude. We therefore conclude that the compositional change of our particles once injected in the EDB may safely be neglected. 
Acknowledgements. The ETH group acknowledges the ETH Research Grant ETH-0210-1. Y. Rudich acknowledges support from the Minerva Foundation with funding from the Federal German Ministry for Education and Research and from the Dollond Charitable Trust. A. J. Huisman was supported by US National Science Foundation under award no. IRFP 1006117. J. P. Reid acknowledges the NERC award NE/M004600/1. The BC/ARI group acknowledges support by the Atmospheric Chemistry Program of the US National Science Foundation under grants AGS-1244918, ATM-0854916, AGS-1244999 and AGS-0904292 and by the US Office of Science (BER), Department of Energy (Atmospheric Systems Research) under grants DE-SC0006980 and DE-SC0011935. We thank Hans Peter Dette, Mian Qi, David Schröder and Adelheid Godt for providing the 3-MBTCA sample and Thomas Berkemeier for helpful discussions.

Edited by: H. Grothe

\section{References}

Abramson, E., Imre, D., Beranek, J., Wilson, J., and Zelenyuk, A.: Experimental determination of chemical diffusion within secondary organic aerosol particles, Phys. Chem. Chem. Phys., 15, 2983-2991, 2013.

Arangio, A. M., Slade, J. H., Berkemeier, T., Poeschl, U., Knopf, D. A., and Shiraiwa, M.: Multiphase chemical kinetics of $\mathrm{OH}$ radical uptake by molecular organic markers of biomass burning aerosols: humidity and temperature dependence, surface reaction, and bulk diffusion, J. Phys. Chem. A, 119, 4533-4544, 2015

Bateman, A. P., Bertram, A. K., and Martin, S. T.: Hygroscopic influence on the semisolid-to-liquid transition of secondary organic materials, J. Phys. Chem. A, 119, 4386-4395, 2015.

Berkemeier, T., Shiraiwa, M., Pöschl, U., and Koop, T.: Competition between water uptake and ice nucleation by glassy organic aerosol particles, Atmos. Chem. Phys., 14, 12513-12531, doi:10.5194/acp-14-12513-2014, 2014.

Bones, D. L., Reid, J. P., Lienhard, D. M., and Krieger, U. K.: Comparing the mechanism of water condensation and evaporation in glassy aerosol, P. Natl. Acad. Sci. USA, 109, 11613-11618, doi:10.1073/pnas.1200691109, 2012.

Booth, A. M., Murphy, B., Riipinen, I., Percival, C. J., and Topping, D. O.: Connecting bulk viscosity measurements to kinetic limitations on attaining equilibrium for a model aerosol composition, Environ. Sci. Technol., 48, 9298-9305, 2014.

Cai, W. D., Ramesh, N., Tihminlioglu, F., Danner, R. P., Duda, J. L., and de Haan, A.: Phase equilibrium and diffusion of solvents in polybutadiene: a capillary-column inverse gas chromatography study, J. Polym. Sci. Pol. Phys., 40, 1046-1055, 2002.

Cohen, M. H. and Grest, G. S.: Liquid-glass transition, a freevolume approach, Phys. Rev. B, 20, 1077-1098, 1979.

Corti, H. R., Frank, G. A., and Marconi, M. C.: Diffusion-viscosity decoupling in supercooled aqueous trehalose solutions, J. Phys. Chem. B, 112, 12899-12906, doi:10.1021/jp802806p, 2008.

Debenedetti, P. G.: Metastable Liquids: Concepts and Principles, Princeton University Press, Princeton, NJ, USA, 1996.

Debenedetti, P. G. and Stillinger, F. H.: Supercooled liquids and the glass transition, Nature, 410, 259-267, 2001.
Demertzis, P. G. and Kontominas, M. G.: Thermodynamic study of water sorption and water vapor diffusion in poly(vinylidene chloride) copolymers, in: Inverse Gas Chromatography, edited by: Lloyd, D. R., Ward, T. C., Schreiber, H. P., and Pizana, C. C., chap. 7, American Chemical Society, Washington, D.C., USA, 77-86, 1989

Dette, H. P., Qi, M., Schroeder, D. C., Godt, A., and Koop, T.: Glass-forming properties of 3-methylbutane-1,2,3-tricarboxylic acid and its mixtures with water and pinonic acid, J. Phys. Chem. A, 118, 7024-7033, 2014.

Duda, J. L.: Molecular diffusion in polymeric systems, Pure Appl. Chem., 57, 1681-1690, 1985.

Ekdawi-Sever, N., de Pablo, J. J., Feick, E., and von Meerwall, E.: Diffusion of sucrose and alpha,alpha-trehalose in aqueous solutions, J. Phys. Chem. A, 107, 936-943, 2003.

Faldi, A., Tirrell, M., Lodge, T. P., and von Meerwall, E.: Monomer diffusion and the kinetics of methyl methacrylate radical polymerization at intermediate to high converstion, Macromolecules, 27, 4184-4192, 1994.

Gillen, K. T., Douglass, D. C., and Hoch, J. R.: Self-diffusion in liquid water to -31 degrees C, J. Chem. Phys., 57, 5117-5119, doi:10.1063/1.1678198, 1972.

Gordon, J. M. and Taylor, J. S.: Ideal copolymers and the 2nd-order transitions of synthetic rubbers. 1. Non-crystalline copolymers, J. Appl. Chem., 2, 493-500, 1952.

Hagiwara, T., Sakiyama, T., and Watanabe, H.: Estimation of water diffusion coefficients in freeze-concentrated matrices of sugar solutions using molecular dynamics: correlation between estimated diffusion coefficients and measured ice-crystal recrystallization rates, Food Biophys., 4, 340-346, 2009.

Hardy, G. F.: Solubility and diffusion of water in acetal polymers, J. Polym. Sci. A2, 5, 671-684, 1967.

Heaton, K. J., Sleighter, R. L., Hatcher, P. G., Hall, W. A., and Johnston, M. V.: Composition domains in monoterpene secondary organic aerosol, Environ. Sci. Technol., 43, 7797-7802, 2009.

Hong, S. U.: Prediction of polymer-solvent diffusion behaviour using free-volume theory, Ind. Eng. Chem. Res., 34, 2536-2544, 1995.

Hosny, N. A., Fitzgerald, C., Tong, C., Kalberer, M., Kuimova, M. K., and Pope, F. D.: Fluorescent lifetime imaging of atmospheric aerosols: a direct probe of aerosol viscosity, Faraday Discuss., 165, 343-356, 2013.

Karlsson, O. J., Stubbs, J. M., Karlsson, L. E., and Sundberg, D. C.: Estimating diffusion coefficients for small molecules in polymers and polymer solutions, Polymer, 42, 4915-4923, 2001.

Kokes, R. J. and Long, F. A.: Diffusion of organic vapors into polyvinyl acetate, J. Am. Chem. Soc., 75, 6142-6146, 1953.

Koop, T., Luo, B. P., Tsias, A., and Peter, T.: Water activity as the determinant for homogeneous ice nucleation in aqueous solutions, Nature, 406, 611-614, 2000.

Koop, T., Bookhold, J., Shiraiwa, M., and Pöschl, U.: Glass transition and phase state of organic compounds: dependency on molecular properties and implications for secondary organic aerosols in the atmosphere, Phys. Chem. Chem. Phys., 13, 19238-19255, 2011.

Kumins, C. A. and Roteman, J.: Diffusion of gases and vapors through polyvinyl chloride-polyvinyl acetate copolymer films. 1. Glass transition effect, J. Polym. Sci., 55, 683-698, 1961. 
Kumins, C. A., Rolle, C. J., and Roteman, J.: Water vapor diffusion through vinyl chloride-vinyl acetate copolymer, J. Phys. Chem., 61, 1290-1296, 1957.

Lambe, A. T., Ahern, A. T., Williams, L. R., Slowik, J. G., Wong, J. P. S., Abbatt, J. P. D., Brune, W. H., Ng, N. L., Wright, J. P., Croasdale, D. R., Worsnop, D. R., Davidovits, P., and Onasch, T. B.: Characterization of aerosol photooxidation flow reactors: heterogeneous oxidation, secondary organic aerosol formation and cloud condensation nuclei activity measurements, Atmos. Meas. Tech., 4, 445-461, doi:10.5194/amt-4-445-2011, 2011.

Lambe, A. T., Cappa, C. D., Massoli, P., Onasch, T. B., Forestieri, S. D., Martin, A. T., Cummings, M. J., Croasdale, D. R., Brune, W. H., Worsnop, D. R., and Davidovits, P.: Relationship between oxidation level and optical properties of secondary organic aerosol, Environ. Sci. Technol., 47, 6349-6357, 2013.

Launay, A., Thominette, F., and Verdu, J.: Water sorption in amorphous poly(ethylene terephthalate), J. Appl. Polym. Sci., 73, 1131-1137, 1999.

Lienhard, D. M., Bones, D. L., Zuend, A., Krieger, U. K., Reid, J. P., and Peter, T.: Measurements of thermodynamic and optical properties of selected aqueous organic and organic-inorganic mixtures of atmospheric relevance, J. Phys. Chem. A, 116, 9954 9968, doi:10.1021/jp3055872, 2012a.

Lienhard, D. M., Zobrist, B., Zuend, A., Krieger, U. K., and Peter, T.: Experimental evidence for excess entropy discontinuities in glass-forming solutions, J. Chem. Phys., 136, 074515, doi:10.1063/1.3685902, 2012b.

Lienhard, D. M., Huisman, A. J., Bones, D. L., Te, Y.-F., Luo, B. P., Krieger, U. K., and Reid, J. P.: Retrieving the translational diffusion coefficient of water from experiments on single levitated aerosol droplets, Phys. Chem. Chem. Phys., 16, 16677-16683, 2014.

Long, F. A. and Thompson, L. J.: Diffusion of water vapor in polymers, J. Polym. Sci., 15, 413-426, 1955.

Mapes, M. K., Swallen, S. F., and Ediger, M. D.: Self-diffusion of supercooled o-terphenyl near the glass transition temperature, J. Phys. Chem. B, 110, 507-511, doi:10.1021/jp0555955, 2006.

McGlashan, M. L.: Deviations from Raoult's law, J. Chem. Educ., 40, 516-518, 1963.

Molinero, V. and Goddard, W. A.: Microscopic mechanism of water diffusion in glucose glasses, Phys. Rev. Lett., 95, 045701, doi:10.1103/PhysRevLett.95.045701, 2005.

Murphy, D. M. and Koop, T.: Review of the vapour pressures of ice and supercooled water for atmospheric applications, Q. J. Roy. Meteorol. Soc., 131, 1539-1565, 2005.

Murray, B. J., Wilson, T. W., Dobbie, S., Cui, Z., Al-Jumur, S. M. R. K., Möhler, O., Schnaiter, M., Wagner, R., Benz, S., Niemand, M., Saathoff, H., Ebert, V., Wagner, S., and Kärcher, B.: Heterogeneous nucleation of ice particles on glassy aerosols under cirrus conditions, Nat. Geosci., 3, 233-237, 2010.

Pajunoja, A., Lambe, A. T., Hakala, J., Rastak, N., Cummings, M. J., Brogan, J. F., Hao, L., Paramonov, M., Hong, J., Prisle, N. L., Malila, J., Romakkaniemi, S., Lehtinen, K. E. J., Laaksonen, A., Kulmala, M., Massoli, P., Onasch, T. B., Donahue, N. M., Riipinen, I., Davidovits, P., Worsnop, D. R., Petaja, T., and Virtanen, A.: Adsorptive uptake of water by semisolid secondary organic aerosols, Geophys. Res. Lett., 42, 3063-3068, 2015.

Park, G. S.: Transport principles - solution, diffusion and permeation in polymer membranes, in: Synthetic Membranes: Science,
Engineering and Applications, edited by: Bungay, P. M., Lonsdale, H. K., and de Pinho, M. N., vol. 181, Reidel, Dordrecht, the Netherlands, 57-107, 1986.

Parker, R. and Ring, S. G.: Diffusion in maltose-water mixtures at temperatures close to the glass transition, Carbohydr. Res., 273 , 147-155, doi:10.1016/0008-6215(95)00120-I, 1995.

Petters, M. D. and Kreidenweis, S. M.: A single parameter representation of hygroscopic growth and cloud condensation nucleus activity, Atmos. Chem. Phys., 7, 1961-1971, doi:10.5194/acp-71961-2007, 2007.

Power, R. M., Simpson, S. H., Reid, J. P., and Hudson, A. J.: The transition from liquid to solid-like behaviour in ultrahigh viscosity aerosol particles, Chem. Sci., 4, 2597-2604, doi:10.1039/c3sc50682g, 2013.

Price, H. C., Murray, B. J., Mattsson, J., O'Sullivan, D., Wilson, T. W., Baustian, K. J., and Benning, L. G.: Quantifying water diffusion in high-viscosity and glassy aqueous solutions using a Raman isotope tracer method, Atmos. Chem. Phys., 14, 38173830, doi:10.5194/acp-14-3817-2014, 2014.

Price, H. C., Mattsson, J., Zhang, Y., Bertram, A. K., Davies, J. F., Grayson, J. W., Martin, S. T., O’Sullivan, D., Reid, J. P., Rickards, A. M. J., and Murray, B. J.: Water diffusion in atmospherically relevant $\alpha$-pinene secondary organic material, Chem. Sci., 6, 4876-4883, 2015.

Price, W. S., Ide, H., and Arata, Y.: Self-diffusion of supercooled water to $238 \mathrm{~K}$ using PGSE NMR diffusion measurements, J. Phys. Chem. A, 103, 448-450, 1999.

Pruppacher, H. R.: Self-diffusion coefficient of supercooled water, J. Chem. Phys., 56, 101-107, 1972.

Ramesh, N., Davis, P. K., Zielinski, J. M., Danner, R. P., and Duda, J. L.: Application of free-volume theory to self diffusion of solvents in polymers below the glass transition temperature: a review, J. Polym. Sci. Pol. Phys., 49, 1629-1644, 2011.

Renbaum-Wolff, L., Grayson, J. W., Bateman, A. P., Kuwata, M., Sellier, M., Murray, B. J., Shilling, J. E., Martin, S. T., and Bertram, A. K.: Viscosity of alpha-pinene secondary organic material and implications for particle growth and reactivity, P. Natl. Acad. Sci. USA, 110, 8014-8019, 2013.

Rickards, A. M. J., Miles, R. E. H., Davies, J. F., Marshall, F. H., and Reid, J. P.: Measurements of the sensitivity of aerosol hygroscopicity and the kappa parameter to the $\mathrm{O} / \mathrm{C}$ ratio, J. Phys. Chem. A, 117, 14120-14131, 2013.

Schatzberg, P.: Diffusion of water through hydrocarbon liquids, J. Polym. Sci. C, 10PC, 87-92, 1965.

Seinfeld, J. H. and Pandis, S. N.: Atmospheric Chemistry and Physics, Wiley and Sons Inc., New York, 1998.

Shiraiwa, M., Ammann, M., Koop, T., and Pöschl, U.: Gas uptake and chemical aging of semisolid organic aerosol particles, P. Natl. Acad. Sci. USA, 108, 11003-11008, doi:10.1073/pnas.1103045108, 2011.

Shiraiwa, M., Zuend, A., Bertram, A. K., and Seinfeld, J. H.: Gasparticle partitioning of atmospheric aerosols: interplay of physical state, non-ideal mixing and morphology, Phys. Chem. Chem. Phys., 15, 11441-11453, 2013.

Smith, R. S. and Kay, B. D.: The existence of supercooled liquid water at $150 \mathrm{~K}$, Nature, 398, 788-791, 1999.

Steimer, S. S., Krieger, U. K., Te, Y.-F., Lienhard, D. M., Huisman, A. J., Luo, B. P., Ammann, M., and Peter, T.: Electrodynamic balance measurements of thermodynamic, kinetic, and optical 
aerosol properties inaccessible to bulk methods, Atmos. Meas. Tech., 8, 2397-2408, doi:10.5194/amt-8-2397-2015, 2015.

Tong, H.-J., Reid, J. P., Bones, D. L., Luo, B. P., and Krieger, U. K.: Measurements of the timescales for the mass transfer of water in glassy aerosol at low relative humidity and ambient temperature, Atmos. Chem. Phys., 11, 4739-4754, doi:10.5194/acp-11-47392011, 2011.

Tonge, M. P. and Gilbert, R. G.: Testing models for penetrant diffusion in glassy polymers, Polymer, 42, 501-513, 2001.

Tonge, M. P., Stubbs, J. M., Sundberg, D. C., and Gilbert, R. G.: Penetrant diffusion in poly(methyl methacrylate) near T-g: dependence on temperature and polymer weight fraction, Polymer, 41, 3659-3670, 2000.

Tromp, R. H., Parker, R., and Ring, S. G.: Water diffusion in glasses of carbohydrates, Carbohyd. Res., 303, 199-205, 1997.

Vignes, A.: Diffusion in binary solutions. Variation of diffusion coefficient with composition, Ind. Eng. Chem. Fundam., 5, 189199, 1966.

Virtanen, A., Joutsensaari, J., Koop, T., Kannosto, J., Yli-Pirila, P., Leskinen, J., Makela, J. M., Holopainen, J. K., Poeschl, U., Kulmala, M., Worsnop, D. R., and Laaksonen, A.: An amorphous solid state of biogenic secondary organic aerosol particles, Nature, 467, 824-827, doi:10.1038/nature09455, 2010.

Vrentas, J. S. and Vrentas, C. M.: Solvent self-diffusion in glassy polymer-solvent systems, Macromolecules, 27, 55705576, 1994.

Vrentas, J. S. and Vrentas, C. M.: Effect of glass transition on the concentration dependence of self-diffusion coefficients, J. Appl. Polym. Sci., 89, 1682-1684, 2003.
Vrentas, J. S., Duda, J. L., and Ling, H. C.: Influence of the glass transition on the solvent self-diffusion in amorphous polymers, J. Polym. Sci. Pol. Phys., 26, 1059-1065, 1988.

Wang, B. B., Lambe, A. T., Massoli, P., Onasch, T. B., Davidovits, P., Worsnop, D. R., and Knopf, D. A.: The deposition ice nucleation and immersion freezing potential of amorphous secondary organic aerosol: Pathways for ice and mixed-phase cloud formation, J. Geophys. Res., 117, D16209, doi:10.1029/2012JD018063, 2012.

Yasuda, H. and Stannett, V.: Permeation, solution, and diffusion of water in some high polymers, J. Polym. Sci., 57, 907-923, 1962.

Zardini, A. A., Krieger, U. K., and Marcolli, C.: White light Mie resonance spectroscopy used to measure very low vapor pressures of substances in aqueous solution aerosol particles, Opt. Express, 14, 6951-6962, 2006.

Zhang, Y., Sanchez, M. S., Douet, C., Wang, Y., Bateman, A. P., Gong, Z., Kuwata, M., Renbaum-Wolff, L., Sato, B. B., Liu, P. F., Bertram, A. K., Geiger, F. M., and Martin, S. T.: Changing shapes and implied viscosities of suspended submicron particles, Atmos. Chem. Phys., 15, 7819-7829, doi:10.5194/acp-15-78192015, 2015.

Zobrist, B., Marcolli, C., Pedernera, D. A., and Koop, T.: Do atmospheric aerosols form glasses?, Atmos. Chem. Phys., 8, 52215244, doi:10.5194/acp-8-5221-2008, 2008.

Zobrist, B., Soonsin, V., Luo, B. P., Krieger, U. K., Marcolli, C., Peter, T., and Koop, T.: Ultra-slow water diffusion in aqueous sucrose glasses, Phys. Chem. Chem. Phys., 13, 3514-3526, doi:10.1039/C0CP01273D, 2011. 